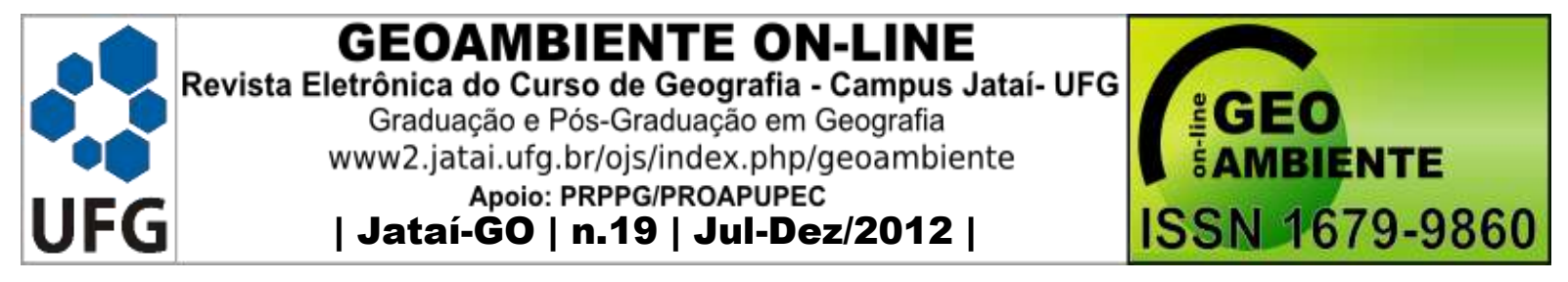

\title{
UMA CARACTERIZAÇÃO GEOAMBIENTAL DA ÁREA DE CONFLUÊNCIA ENTRE OS RIOS BOIADEIRO E PARNAÍBA E CIRCUNVIZINHANÇAS NA PARTE CENTRAL DO MUNICÍPIO DE DOM AQUINO - MT
}

\author{
Lucelma Aparecida Nascimento ${ }^{1}$, Leonardo Cristian Rocha ${ }^{2}$, Josdyr Vilhagra ${ }^{3}$,
}

Deocleciano Bittencourt Rosa ${ }^{4}$

(1 - Université Rennes, Professora MSc, Bolsista de Doutorado Pleno da CAPES Laboratoire COSTEL/Departement de Géographie et Amenagement de l'Espace. 6, Av. Gaston Berger, Bloc N. 35000 Rennes, Cedex - France. lucelmamt@yahoo.com.br, 2 Universidade Federal de São João Del Rei. Instituto de Geociências. Avenida Visconde do Rio Preto, s/nº - Colônia do Bengo - CEP 36301-360 - São João Del Rei, MG; 3 Universidade Federal de Mato Grosso, Mestrando do Programa de Pós-Graduação em Geografia/Departamento de Geografia. - Av. Fernando Correa da Costa 2367. Cidade Universitária, Boa Esperança. 78.060-900 - Cuiabá, MT; 4 - Universidade Federal de Mato Grosso. Departamento de Geografia. Programa de Pós-Graduação em Geografia. Av. Fernando Correa da Costa 2367. Cidade Universitária, Boa Esperança. 78060-900 Cuiabá, MT, dbrosa@terra.com.br)

\section{Resumo}

Este artigo está referido a uma caracterização geoambiental da área de confluência entre os rios Boiadeiro e Parnaíba e circunvizinhanças, localizadas na parte central do município de Dom Aquino, no Planalto dos Alcantilados, sudeste do Estado de Mato Grosso. Regionalmente foram desenvolvidos estudos, acerca dos aspectos fisiográficos, que incluem os dados climáticos, geológicos, geomorfológicos, pedológicos, hídricos e da cobertura vegetal, que se constituíram nas bases para a divisão desta área em unidades geoambientais. Todos estes trabalhos tiveram como objetivo principal a realização de um levantamento na escala regional de 1:100.000. Foram utilizadas como base para esses estudos as cartas temáticas do Projeto RADAMBRASIL editadas em 1982 e da Companhia de Pesquisa de Recursos Minerais em 2004, ampliados para a escala de interesse, assim como imagens orbitais dos satélites LANDSAT/TM-07 e CBERS 1, 2 e 3, obtidas desde 2001, até março de

Artigo recebido para publicação em 27 de Setembro de 2012 


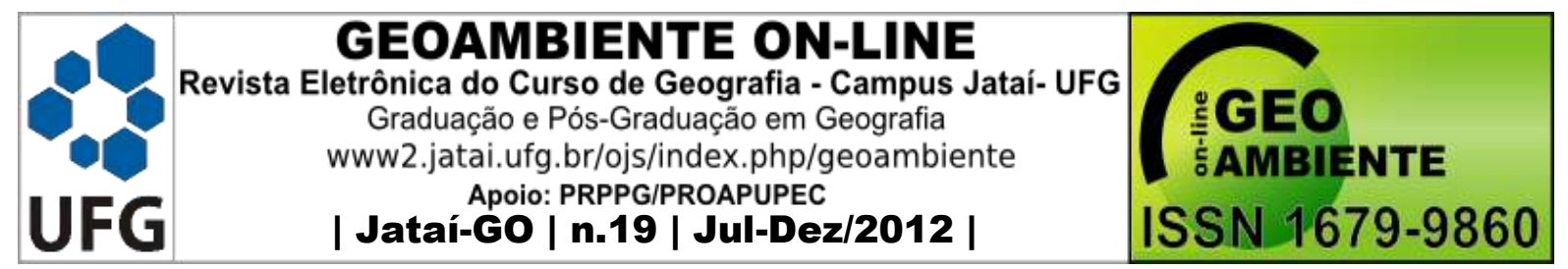

2011, para ser realizado um estudo comparativo com as fotografias aéreas pancromáticas que foram editadas pelo Acordo AST-USAF (United States Air Force)/Cruzeiro do Sul em 1964.

Palavras Chaves: Dom Aquino, Rio Boiadeiro, Planalto dos Alcantilados, Nitossolos, geoambiental.

\section{Resume}

UNE CARACTERISATION GEOLOGIQUE ENVIRONNEMENTALE DE L'AIRE DE CONFLUENCE ENTRE LES RIVIERES BOIADEIRO ET PARNAIBA ET ALENTOURS DANS LA PARTIE CENTRALE DU DISTRICT DE DOM AQUINO MT

Cet article est référé à une caractérisation géologique environnentale de l'aire de confluence entre les rivières Boiadeiro et Parnaíba et alentours localisées dans la partie centrale du district de Dom Aquino dans le Planalto dos Alcantilados, au sud-est de l'Etat de Mato Grosso. Régionalement ont été développés des études, sur les aspects physiographiques qu'incluent des données climatiques, géologiques, géomorphologiques, pédologiques, hydriques et de la couverture végétale, qui ont se constitué dans les bases pour la division de cet aire dans des unités géologiques environnementales. Tous ces travaux ont eu comme objectif principal la réalisation d'un levé à l'échelle régionale de 1:100.000. Nous avons utilisés comme base pour ces études les cartes thématiques du Projeto RADAMBRASIL editées en 1982 et de la Companhia de Pesquisa de Recursos Minerais en 2004, agrandies par l'échelle d'intérêt, ainsi comme les images de télédétection des satellites LANDSAT/TM-07 et CBERS 1, 2 et 3, obtenues dès 2001 jusqu'à mars 2011, par la réalisation d'une comparaison avec les photographies aériennes pancromatiques qui ont été effectuées par l'Accord $A S T$ USAF (United States Air Force)/Cruzeiro do Sul en 1967.

Mots Clés: Dom Aquino, Rivière Boiadeiro, Plateau dos Alcantilados, Nitosols, géologique environnementale.

\section{Abstract}

AN ENVIRONMENTAL GEOLOGICAL CHARACTERIZATION OF THE CONFLUENCE AREA BETWEEN THE BOIADEIRO AND THE PARNAÍBA 


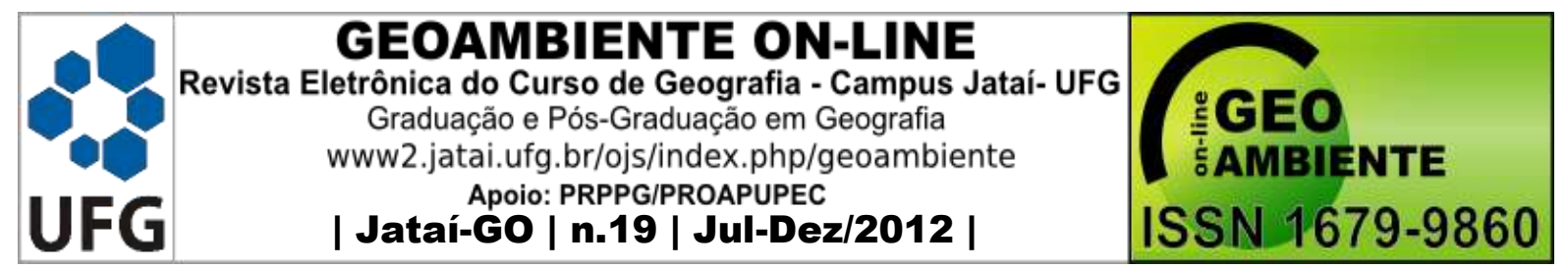

RIVERS AND SURROUDINGS IN THE CENTRAL PART OF THE DOM AQUINO DISTRICT - MATO GROSSO STATE - BRAZIL

This article is related to a environmental geological geoambiental characterization of the area of confluence between the Boiadeiro and Parnaíba rivers and surroundings located in the central part of the Dom Aquino district, in the Planalto dos Alcantilados, southeast of the Mato Grosso State. Regionally studies had been developed, concerning physiographical aspects, that include the data climatic, geologic, geomorphologic, pedological, water and the vegetal covering, that if had constituted in the bases for the division of this area in environmental geological units. All these works had as objective main the accomplishment of a survey in the regional scale of 1:100.000. The thematic letters of RADAMBRASIL Project edited in 1982 and of the Company of Research of Mineral Resources in 2004 had been used as base for these studies, extended for the interest scale, as well as orbital images of satellites LANDSAT/TM-07 and CBERS 1, 2 and 3, gotten since 2001, until March of 2011, to be carried through a comparative study with the panchromatic air photographs that had been edited by Agreement AST-USAF (United States Air Force)/Cruzeiro do Sul in 1967.

Key words: Dom Aquino, Boiadeiro River, Planalto dos Alcantilados, Nitosoils, Savanah, Environmental.

\section{1 - INTRODUÇÃO}

Este trabalho contém a descrição dos aspectos fisiográficos que foram obtidos, através de estudos iniciais na literatura geográfica geológica, e de um levantamento posterior na escala regional de 1:100.000, da área de confluência do rio Boiadeiro com o rio Parnaíba, e circunvizinhanças, para a caracterização da mesma em unidades geoambientais. Esta área foi delimitada no município de Dom Aquino, localizado na parte sudeste do Estado de Mato Grosso.

A área delimitada para estudos está inserida aproximadamente, entre as coordenadas geográficas de latitudes $15^{\circ} 38^{\prime} 04^{\prime \prime}$ e $15^{\circ} 43^{\prime} 02^{\prime}$ ' Sul e longitudes $54^{\circ} 45^{\prime} 02^{\prime}$ " e $54^{\circ} 52^{\prime} 28^{\prime \prime}$ Oeste de Greenwich, e as coordenadas UTM de datum: verticais 730000 e 740000 e horizontais 8260750 e 8272000 . As altitudes regionalmente se situam entre 400 a 640 metros (Figura 1). 


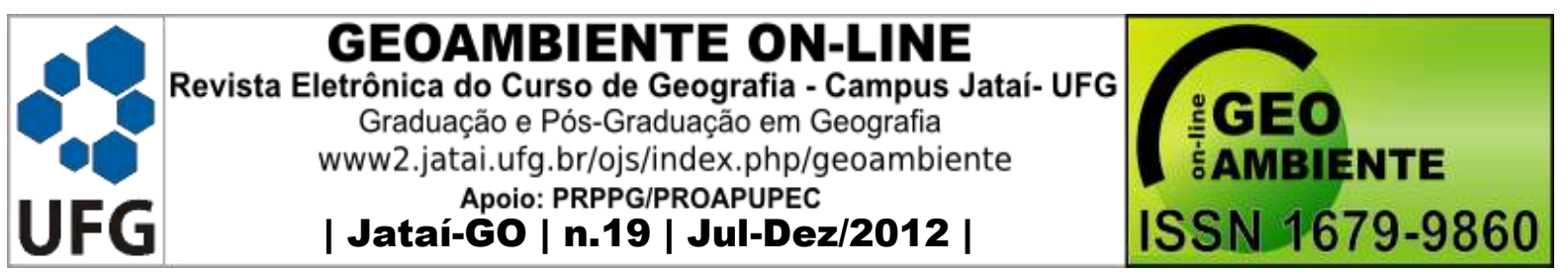

Figura 1 - Carta de localização da área de estudos no município de Dom Aquino, MT.

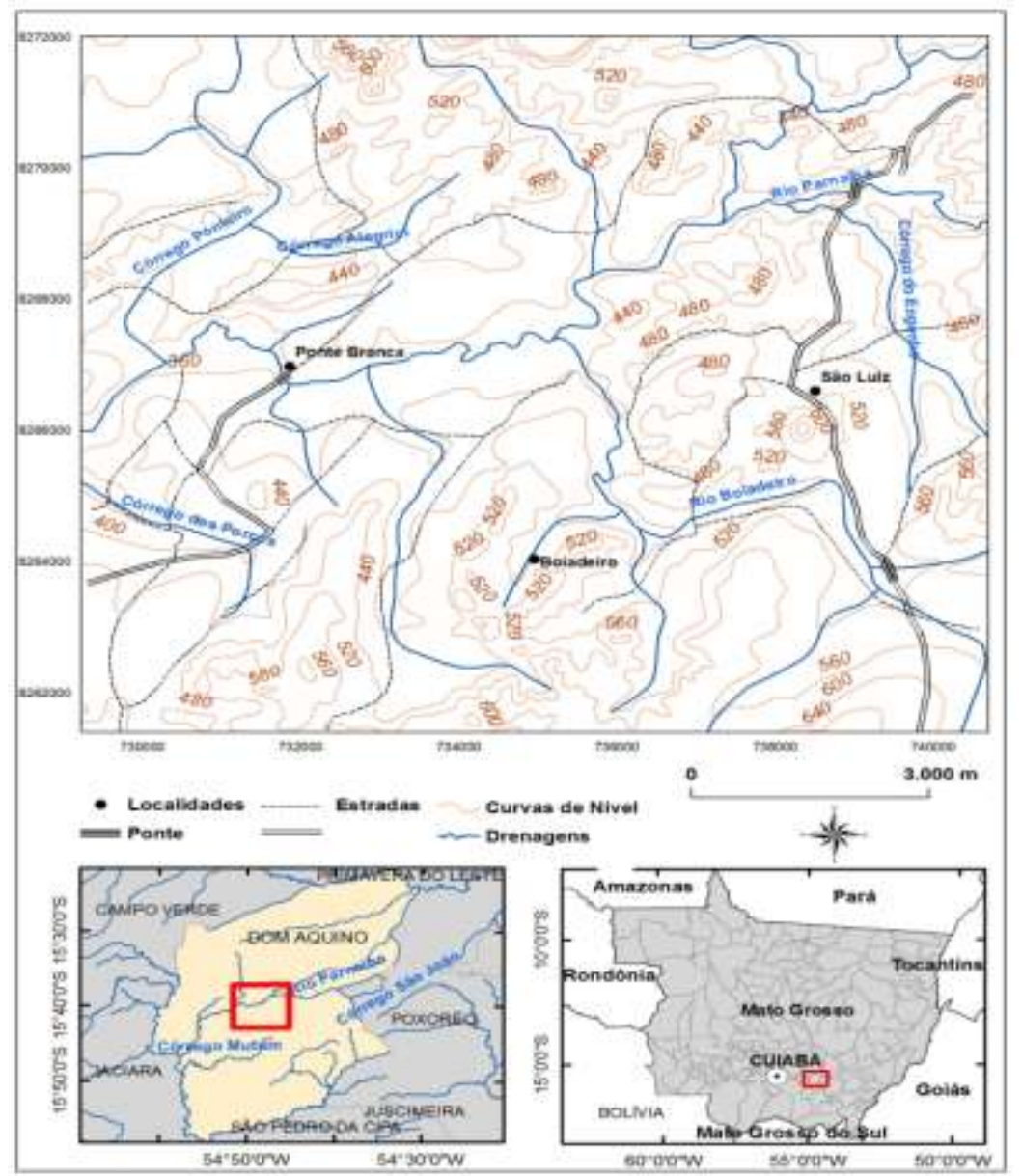

Fonte - SEPLAN/MT (2007), modificado por Valdenir Santana Araujo em (2012).

O objetivo principal deste trabalho foi o de determinar as condições climáticas atuais desta área, assim como sua constituição geológica, geomorfológica, pedológica e hídrica, para sua divisão em unidades geoambientais.

\section{2 - PROCEDIMENTOS METODOLÓGICOS}

Os procedimentos metodológicos utilizados neste trabalho envolveram duas etapas, assim distribuídas:

\section{1 - Etapas dos Procedimentos Teóricos}

Estas primeiras etapas de estudos foram levadas a efeito nas dependências do Departamento de Geografia do ICHS/UFMT, com trabalhos iniciais de compilação bibliográfica e confecção de mapas índices, depois da observação dos aspectos físico-bióticos, 


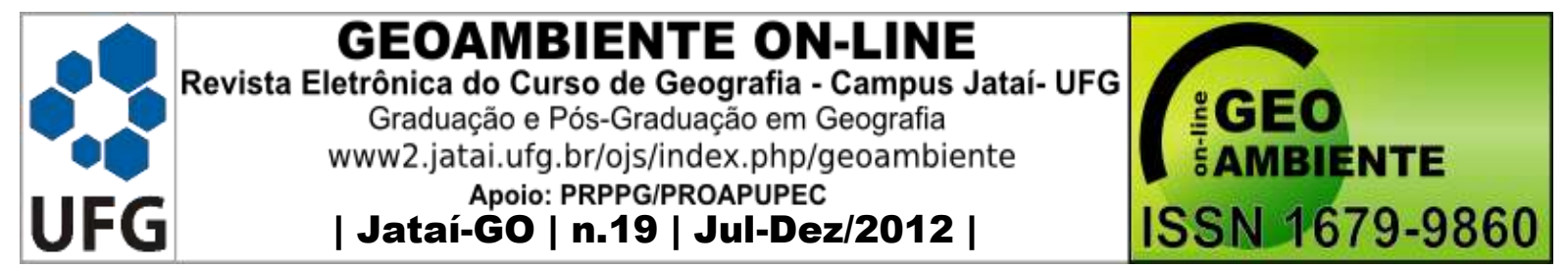

para a caracterização da cobertura vegetal regional através de fotografias aéreas verticais pancromáticas obtidas pelo AST-10/USAF (United States Air Force)/Cruzeiro do Sul, em 1967.

Estas fotografias foram comparadas com as imagens do satélite LANDSAT/TM -7, bandas 3, 4 e 5, obtidas em 2004, e com as mais recentes datadas de 02/08/2005 e 14, 20, e 23/01/2006, cuja fonte foi o site norte americano Earth Science Data Interface (ESDI) Administração Nacional de Aeronáutica e Espaço - NASA. Entretanto, com a desativação do satélite $L A N D S A T / T M-7$, foram utilizadas também nesta etapa, as imagens obtidas pelo Satélite CBERS 2 (China-Brazil Earth Resources Satellite), Satélite Sino-Brasileiro de Recursos Terrestres, nas bandas 2, 3, 4 e 5 (red/green/gray and blue), órbitas/pontos 168/116 e 168/117, datadas de 3 de agosto de 2007, fornecidas pelo Instituto Nacional de Pesquisas Espaciais - INPE, utilizando-se o conhecimento das técnicas de sensoriamento remoto.

As cartas utilizadas como bases cartográficas foram os mapas planialtimétricos da D.S.G., do Ministério do Exército, atual Centro de Cartografia Digital e do IBGE, nas escalas 1:250.000 e 1:100.000, sendo utilizadas respectivamente as Folhas de Dom Aquino de sigla SD.21-Z-D, MIR - 389 (1:250.000) e CN - 30/100, MI 2201 de índice de nomenclatura SD.21-Z-D-V (1:100.000), publicadas em 1975 (1:100.000) e 1982 (1:250.000).

Foram utilizadas também, nesta fase as cartas temáticas elaboradas pelo Projeto RADAMBRASIL, Folhas na escala 1:1000.000, SD.21/Cuiabá, de Amaral et al. (1982), vegetação, Barros et al. (1982), geologia, Ross e Santos (1982), geomorfologia, Oliveira et al. (1982), pedologia e levantamento exploratório dos solos e Roessing et al. (1982) uso potencial da terra, e aquelas de Bittencourt Rosa et al. (2002) e da CPRM (2004).

$\mathrm{Na}$ determinação das localizações das toponímias e vias de acesso, foi utilizado como base cartográfica o mapa rodoviário do Estado de Mato Grosso, confeccionado pela Secretaria de Infraestrutura do Estado de Mato Grosso - SINFRA, em 2009, na escala 1:1.500.000.

\section{2 - Etapas dos Procedimentos Práticos}

Estas etapas foram relacionadas aos trabalhos de campo onde foi efetivada uma análise dos aspectos fisiográficos, com o objetivo de conhecer os recursos naturais e seu grau de reversibilidade. Estes trabalhos foram desenvolvidos em três fases, onde foi possível caracterizar de uma maneira geral os aspectos climáticos, geológicos, geomorfológicos, pedológicos, hidrológicos e da cobertura vegetal, que são os temas considerados importantes dentro de uma área de estudos para a sua caracterização geoambiental. 


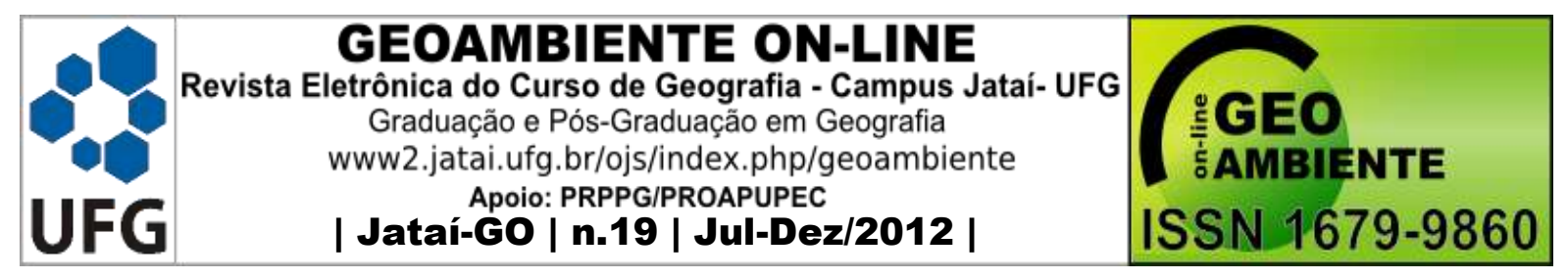

\section{3 - FUNDAMENTAÇÕES BIBLIOGRÁFICA E TEÓRICA}

Convém salientar que alguns trabalhos contendo dados, acerca dos aspectos fisiográficos, já foram realizados na área da bacia hidrográfica do rio Parnaíba e circunvizinhanças. Entretanto, no que tange a estudos geoambientais na bacia do rio Boiadeiro, e na faixa de confluência do mesmo com o rio Parnaíba eles nunca foram enfatizados em nível de detalhes.

Os dados mais concretos desta região estão relatados a Almeida (1964), que realizou estudos acerca da Geologia do Centro-Oeste Matogrossense, numa obra que retrata diversos dados acerca da bacia do rio Paraguai. Pelo Projeto RADAMBRASIL (1982), na Folha SD.21/Cuiabá ao milionésimo, podemos citar os trabalhos precitados, que possuem relatos acerca da área abrangida pelas bacias dos rios Boiadeiro e Parnaíba.

Outros estudos regionais estão relacionados à Vailant (1999), que realiza uma caracterização geoambiental no setor centro-leste do município de Dom Aquino, tendo como ponto principal a localidade de São Luiz, na bacia hidrográfica do médio rio Parnaíba. Ferreira (2002) apresenta o resultado de seus estudos geoambientais desenvolvidos no médio curso do rio Parnaíba no município de Dom Aquino, associados com a biodiversidade.

\section{4 - ASPECTOS FISIOGRÁFICOS}

\section{$4.1-$ Clima}

No que tange aos aspectos fisiográficos inicialmente, podemos considerar para esta área e circunvizinhanças um clima que não é uniforme, segundo a classificação climática para as grandes linhas do clima de Durand-Dastès (1968), modificada por Estienne e Godard (1970) e apresentada por Tardy (1986). Este clima é considerado como o de número 2 (dois), ou seja, tropical quente a estações contrastadas, onde uma é seca e outra chuvosa.

Nestas duas estações podem ser evidenciados seis meses chuvosos (dezembro a março), e seis meses quentes (abril a setembro) com variações de extremos quentes a frios secos. Às temperaturas se situam na faixa de $24^{\circ}$ a $36^{\circ} \mathrm{C}$, no decurso da estação chuvosa, e a pluviometria média da região é de $1700 \mathrm{~mm}$, com uma máxima mensal de $15 \mathrm{~mm}$ a $300 \mathrm{~mm}$ 


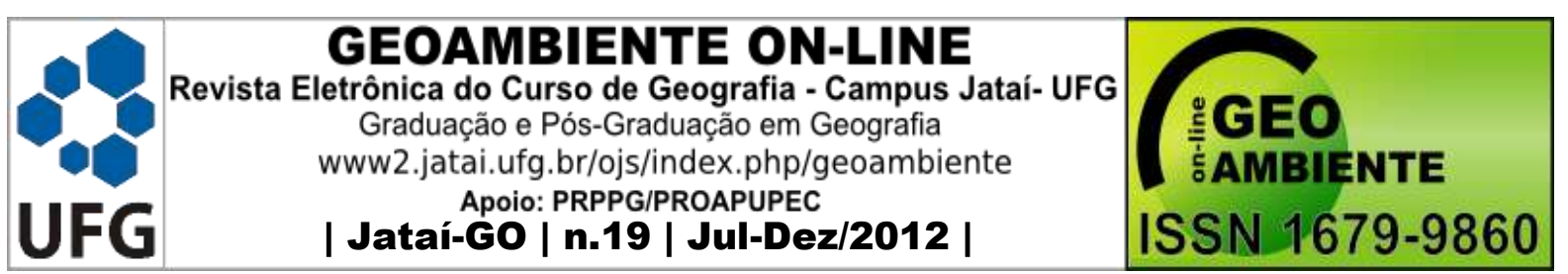

aproximadamente, e uma mínima mensal de $20 \mathrm{~mm}$ a $50 \mathrm{~mm}$, durante a estação seca, onde as temperaturas oscilam entre $30^{\circ}$ a $38^{\circ} \mathrm{C}$ (MAITELLI, 2005).

\section{2 - Geologia Local}

Geologicamente a área em questão e suas circunvizinhanças apresentam-se constituídas por um conjunto litológico, que evidenciam episódios deposicionais que tiveram lugar desde o Carbonífero até os dias atuais. Este conjunto está representado por rochas pertencentes às Formações Aquidauana (Carbonífero Médio - Permiano Inferior) e Palermo (Permiano Médio ao Superior), ao Grupo Parecis (Formações Paredão Grande, Cachoeira do Bom Jardim e Utiariti - Cretáceo Superior), Coberturas Detrito-Lateríticas referidas ao Terciário e as Aluviões recentes (BARROS et al. 1982, WESKA, 1996, BITTENCOURT ROSA et al. 2002 e CPRM 2004) (Figura 2).

Figura 2 - Esboço da geologia da área da bacia hidrográfica do rio Boiadeiro e adjacências.

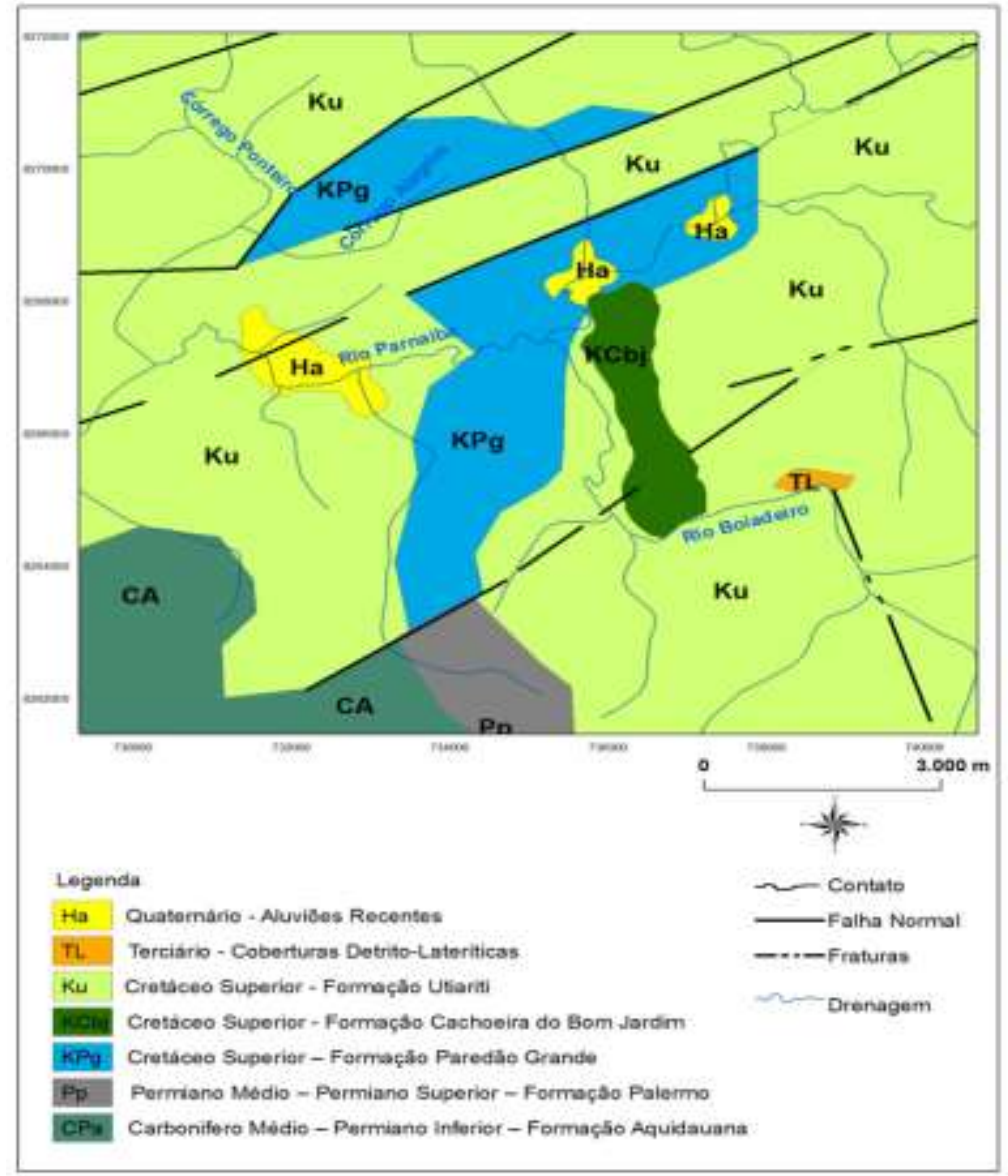

(Fonte - Barros et al. 1982, Weska, 1996 e Bittencourt Rosa, 2005, 2009)(Organizado por Valdenir Santana Araujo, março 2012). 


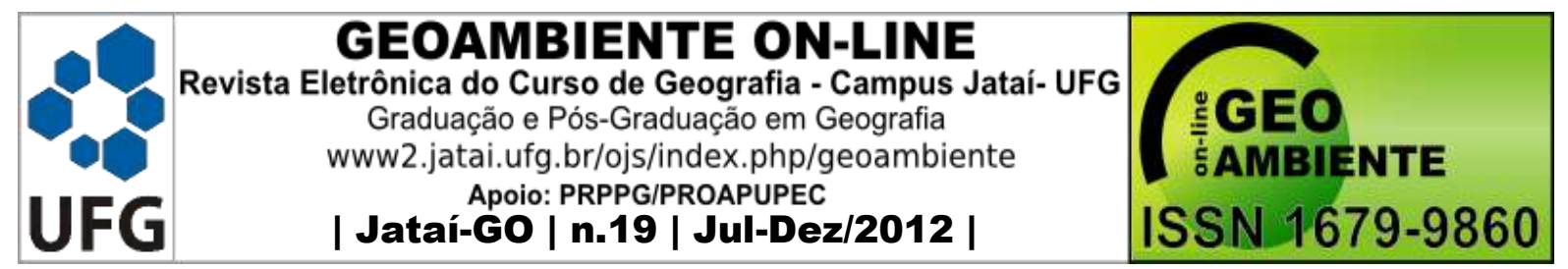

4.2.1 - Formação Aquidauana

Esta unidade litoestratigráfica (Mendes, 1984), foi descrita primeiramente, por Derby (1895), no município de Aquidauana no antigo Estado do Mato Grosso. Ela está posicionada como pertencente ao Grupo Itararé, e este ao Super Grupo Tubarão.

Nos municípios de Dom Aquino e Poxoréu, e regionalmente, ela se constitui de clastos grossos (diamictitos, arenitos grossos a conglomeráticos) e finos (siltitos, argilitos e arenitos finos). A Formação Aquidauana se estende sobre o flanco oeste da Serra das Parnaíbas e remonta largamente, rumo aos topos da Serra de São Bento. O contato da Formação Aquidauana, com a Formação Palermo sobrejacente se faz por discordância angular.

\subsection{2 - Formação Palermo}

Esta formação que foi descrita por White (1908), deve esta denominação a cidade homônima Palermo, situada no Estado de Santa Catarina (Região Sul do Brasil). Ela pertence ao Grupo Guatá, e este ao Super Grupo Tubarão. A Formação Palermo ocupa uma pequena superfície nos municípios de Dom Aquino e Poxoréu, e se encontra essencialmente, sobre os flancos oeste das Serras das Parnaíbas e de São Bento.

Localmente ela pode ser encontrada aflorando na localidade de Boiadeiro de Cima, e está constituída litologicamente, por um conglomerado basal avermelhado e róseo, intercalado com seixos de arenitos quartzíticos, camadas de argilas violetas, níveis de opalas esbranquiçadas, esverdeadas, cinzentas e azulada intercalados, com siltitos esbranquiçados e avermelhados e de sílex esbranquiçados e azulados. Níveis de brechas com uma matriz opalizada, folheada e levemente ondulada, de arenitos quartzíticos, de arenitos conglomeráticos e a presença de coquinas silicificadas são encontrados nesta fase.

\subsection{3 - Grupo Parecis}

A denominação de Grupo Parecis foi proposta por Barros et al. (1982), em face do predomínio territorial geográfico-geológico desta unidade e de suas características. Corresponde ao conjunto litológico que delimita as Bacias do Alto Rio Paraguai e Amazônica.

Uma síntese dos resultados de estudos acerca do Cretáceo Superior no Estado de Mato Grosso foi publicada por Weska (2006). Esse autor realiza uma revisão das unidades litoestratigráficas Grupo Parecis e Grupo Bauru fazendo uma comparação entre as mesmas, 


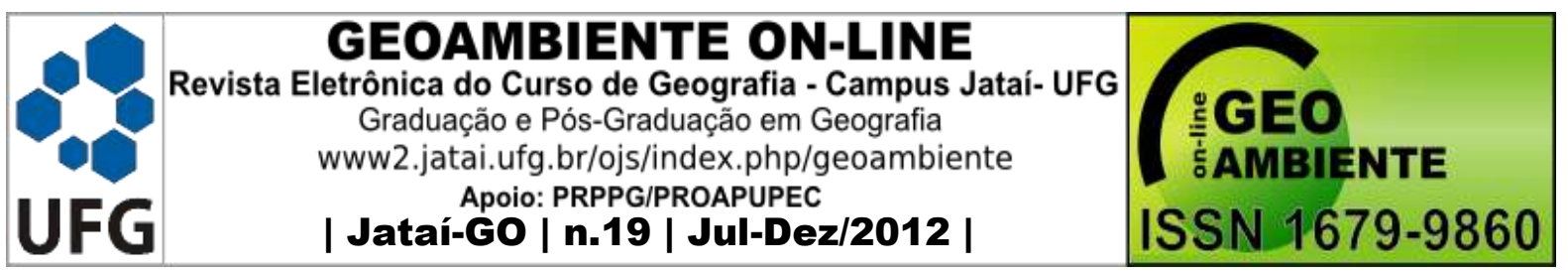

isto porque, a constituição litológica destas duas unidades é idêntica. Desta maneira Weska (2006) concluiu que, por ser o Grupo Parecis mais antigo na escala geológica do estado seria evidente, que uma nova coluna estratigráfica fosse apresentada, com apenas a presença do Grupo Parecis. A constituição litológica desta unidade, doravante estará assim distribuída da base para o topo: Formações: Paredão Grande, Salto das Nuvens, Cachoeira do Bom Jardim e Utiariti.

$\mathrm{Na}$ bacia do rio Boiadeiro na constituição do Grupo Parecis, somente afloram as unidades litoestratigráficas Formações Paredão Grande constituída por soleiras ou sills de basaltos, intertrapeados em arenitos intensamente silicificados, Cachoeira do Bom Jardim (arenitos, calcários, margas e calcretes), e Utiariti onde predominam conglomerados na base e arenitos, contendo intercalações de siltitos, níveis de sílex e de opalas, e silcretes no topo (BARROS et al. 1982, WESKA, 1996, e BITTENCOURT ROSA, 2005, 2009).

\subsection{4 - Coberturas Detrito Lateríticas}

Estas Coberturas Detrito Lateríticas ou lateritas estão dispostas em discordância erosiva recobrindo praticamente todas as unidades da área em apreço. As espessuras podem variar de 0,5 a 3 metros, estando constituídas por detritos eluvionares, coluvionares e aluvionares. Os detritos aluvionares estão relacionados às redes hidrográficas do rio Boiadeiro e Parnaíba. As lateritas constituem crostas de óxido de ferro de cor avermelhada escura, e ocorrem maciçamente, ou em oólitos e pisólitos, por vezes, irregularmente. As formas maciças estão caracterizadas por níveis de crostas regulares de espessura de alguns centímetros $(0,5$ a $5 \mathrm{~cm})$.

\subsection{5 - Aluviões Recentes}

As aluviões estão relacionadas localmente, às bacias dos rios: Boiadeiro e Parnaíba, e seus afluentes regionais. Elas se constituem por uma matriz areno-argilosa fina a grossa, que engloba geralmente, fragmentos, cascalhos, e seixos de quase todos os elementos rochosos que constituem as unidades subjacentes. Elas compreendem um conjunto de sedimentos, localizados nas margens e nos leitos dos rios Boiadeiro e Parnaíba e dos tributários dos mesmos.

Estes sedimentos sofrem a influência periódica das cheias, ficando parte do tempo alagados, sendo por isso produtos do transporte de solos por intervenção das correntes de 


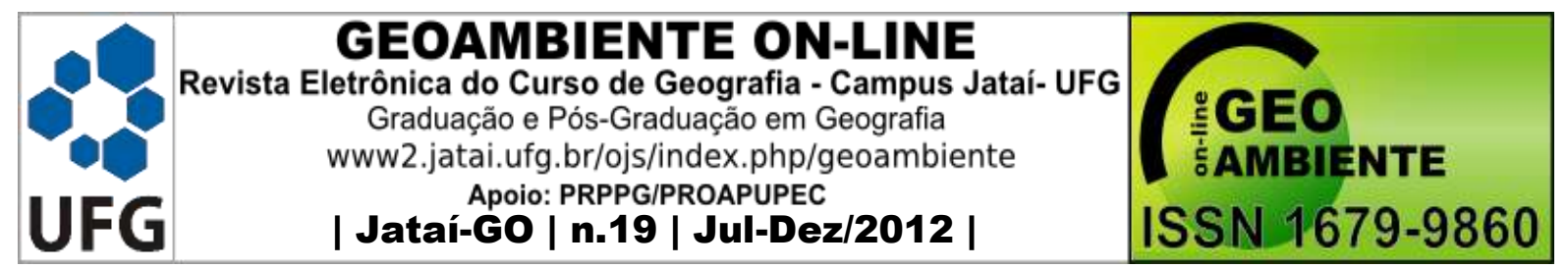

água, as quais vão formando camadas sucessivas em distintos horizontes com depósitos constituídos, muitas vezes de areia, silte, argila, concreções ferruginosas, silicosas, entre outros.

\section{3 - Geomorfologia}

A área de estudos se descortina através da unidade geomorfológica Planalto dos Alcantilados (Almeida, 1948, 1954), que abrange toda parte sudeste do Estado de Mato Grosso (ROSS e SANTOS, 1982, e BITTENCOURT ROSA et al. 2002).

Esta unidade geomorfológica descortina-se, notadamente, como seções topográficas interdigitadas no lado sul da Chapada dos Guimarães, com exceção segundo Ross e Santos (1982) dos relevos de aspecto residual, que caracterizam sua parte sudeste. Regionalmente na área de confluência dos rios Boiadeiro e Parnaíba, dois compartimentos geomorfológicos são distintos, com o primeiro ocorrendo nas partes mais baixas da área e de relevo plano a parcialmente ondulado, e corresponde verdadeiramente aos vales do alto rio São Lourenço e do rio Parnaíba, e se descortina em altitudes que oscilam entre 200 a 400 metros.

O segundo compartimento está caracterizado por uma superfície topograficamente, ondulada resultante da atuação de intensos processos erosivos, cujos detritos erodidos foram carreados, e depositados na imensa bacia intracratônica do Pantanal, localizada ao sul da presente área. As altitudes variam entre 400 a 560 metros, estando referido ao relevo das cornijas e escarpas do Morro do Chibiu (BITTENCOURT ROSA et al. 2002).

\section{$4.4-$ Solos}

A área de estudo está representada pelos seguintes tipos de solos: Solos Concrecionários, Latossolos, Cambissolos, Neossolos Litólicos e Quartzarênicos, Argissolos, Nitossolos e Organossolos. (Dados obtidos a partir de trabalhos de campo e de estudos de OLIVEIRA et al. (1982) e BITTENCOURT ROSA et al. (2002), com adaptação ao Sistema Brasileiro de Classificação dos Solos da EMBRAPA (1999, 2006) e de MOREIRA e VASCONCELOS (2007).

De uma maneira geral estes solos são arenosos, argilosos, sílticos e cascalhosos. São produtos da alteração dos conglomerados, arenitos, calcários, margas e basaltos. O pH varia entre 3,7 a 5,2. Predominam os latossolos, neossolos quartzarênicos e os nitossolos, estes 


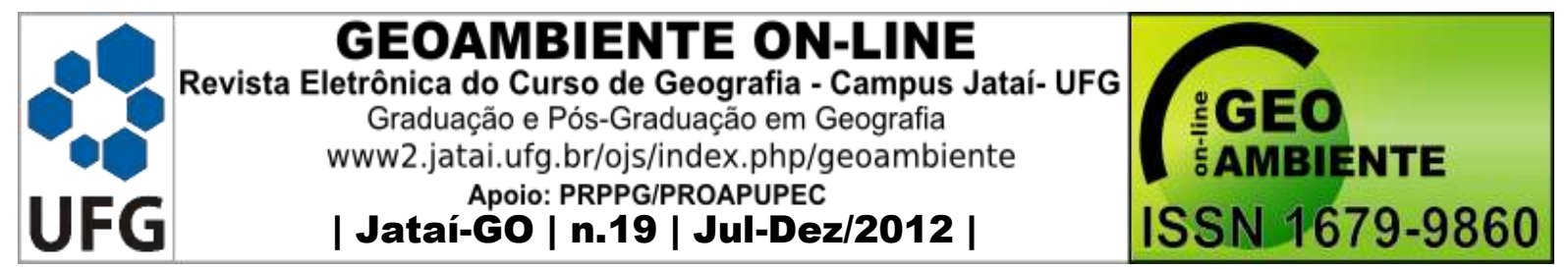

últimos correspondem às antigas terras roxas. Eles ocorrem geralmente como produto de alteração das rochas basálticas, pertencentes à Formação Paredão Grande.

\section{5 - Cobertura Vegetal}

A cobertura vegetal está representada pelo Cerrado (Savana) como presença do Campo Cerrado (Savana Arbórea Aberta), Matas Ciliares e Galerias, Cerradão (Savana Arbórea Densa), Áreas Desmatadas e Áreas Reflorestadas.

As áreas desmatadas foram posicionadas aqui em face do aproveitamento das mesmas para implantações de sítios residenciais, cultivos e pastagens, enquanto que, as áreas reflorestadas foram desmatadas, para serem reflorestadas principalmente por eucaliptos (AMARAL et al. 1982 e BITTENCOURT ROSA et al.2002).

\section{6 - Hidrologia}

Do ponto de vista hidrológico a bacia hidrográfica do rio Boiadeiro pertence à bacia do rio Parnaíba, e esta a bacia do Alto Rio São Lourenço. Elas estão representadas por estas redes de drenagens e seus respectivos afluentes.

$\mathrm{O}$ rio Boiadeiro drena a área inicialmente, no sentido $\mathrm{SE}-\mathrm{NW}$, em seu maior curso, para depois infletir para NE-SW, encaixado numa zona de fraturas. Logo em seguida possui inflexões menores, para NW-SE, SW-NE, e novamente SE-NW, até jogar suas águas no rio Parnaíba.

\section{5 - CARACTERIZAÇÃO GEOAMBIENTAL}

Os estudos geoambientais associados com Geomorfologia podem ser evidenciados na caracterização de determinados espaços geográficos e geológicos. Estudos realizados dentro deste enfoque pelo IBGE (1994) e por Del'Arco et al. (1995), consideram que um mapa geoambiental se constitui no ponto de apoio para as avaliações acerca da qualidade ambiental de uma área, já que ele determina o meio físico-biótico, onde se desenrolam as ações políticas e as pressões socioeconômicas, que são as outras variáveis que foram examinadas nestes estudos.

O mapa geoambiental para Del'Arco et al. (1995), é a representação da compartimentação de um espaço geográfico físico, a partir da análise das interrelações de seus principais constituintes como o clima, a geologia, o relevo, os solos, a rede hidrográfica e a 


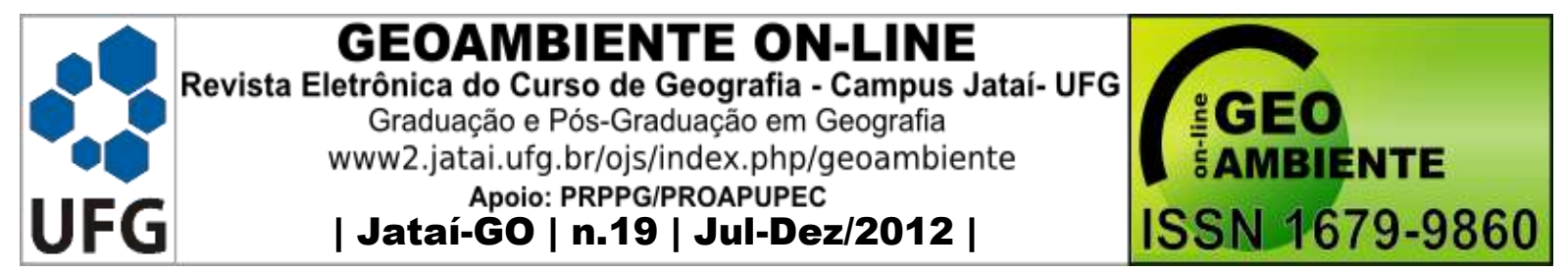

vegetação, em consonância com os dados contidos nos Princípios da Teoria Geral de Sistemas de Bertalanffy (1975) e no Esboço do Modelo de Divisão da Paisagem Física de Bertrand (1968).

\section{1 - Dados acerca da Teoria Geral dos Sistemas}

O enfoque sistêmico ou a essência do pensamento é a ideia de elementos que se associam e constituem conjuntos para realizar objetivos. Ludwig Von Bertalanffy, cientista alemão, um dos mais importantes pensadores acerca do enfoque sistêmico é que propôs a Teoria Geral dos Sistemas.

Na consideração de Maximiniano (2004) que explora "todas" as "totalidades" esta teoria tem duas ideias básicas:

a) A realidade é constituída de sistemas, que são concebidos a partir de elementos interdependentes. A realidade não é feita de elementos isolados, sem qualquer relação entre si. b) Para se entender a realidade, é importantíssima a análise não somente dos elementos isolados, e sim de suas interrelações.

A tecnologia e a sociedade, segundo Bertalanffy (1971), se tornaram tão complexas que as soluções tradicionais não são mais suficientes. É necessário utilizarmos abordagens de naturezas: holística ou sistêmica, generalista ou interdisciplinar.

Desta forma segundo Maximiniano (2004), em concordância esse autor, a Teoria Geral dos Sistemas é a reorientação do pensamento e da visão, a partir da introdução dos sistemas como um novo paradígma científico, que contrasta com o paradígma analítico, mecanístico e linear, de causa e efeito, da ciência clássica.

\section{2 - O Esboço do Modelo de Divisão da Paisagem Física}

A partir da ideia de que neste trabalho temos como enfoque principal uma caracterização geoambiental, apresentamos desta maneira o modelo hierárquico de Bertrand (1968) e os estudos de Bertrand e Bertrand (1991), através do Esboço Metodológico do Modelo de Divisão da Paisagem Física, que há mais de quatro décadas e meia se constituem nos alicerces para os estudos geoambientais, no que se refere à caracterização de uma determinada região dividida em unidades ambientais, segundo uma ordem hierárquica, que de uma parte determina os Táxons [corresponde a qualquer unidade taxionômica, sem especialização de categoria. Podendo ser gênero, espécie, entre outros (Ferreira, 2002)] 


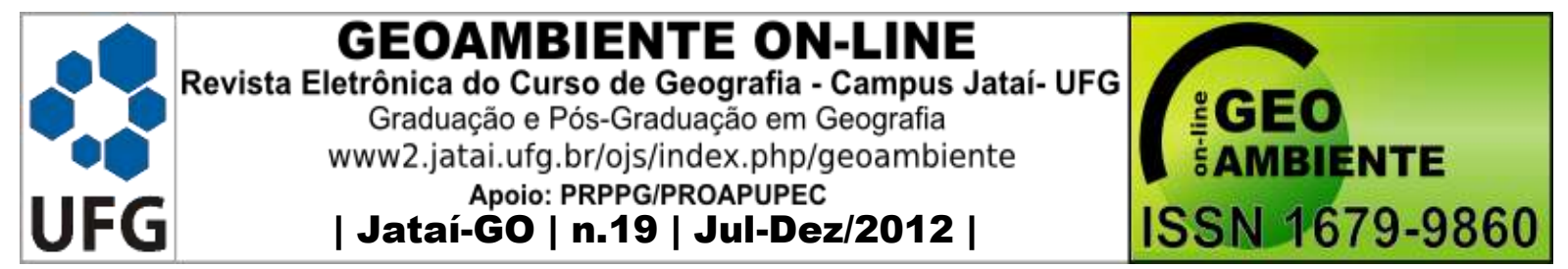

maiores como a Zona, o Domínio e a Região Natural, e de outra parte os Táxons menores como os Geossistemas ou Sistemas Naturais, os Geofácies e os Geótopos, como as unidades físicas da paisagem.

O qualificativo de Zona é explicado por Bertrand (1968) como imperativamente, associado ao conceito de zonalidade planetária, sendo então relatado aos conjuntos de primeira grandeza (zona temperada). Realmente a Zona se define inicialmente, por suas oscilações climáticas e suas "biotas", acessoriamente por certas megaestruturas (Ex.; os escudos das áreas tropicais).

O Domínio está relacionado com as unidades de segunda grandeza. O domínio mediterrâneo é um exemplo deste tipo com suas paisagens vigorosamente, individualizadas. Desta forma define-se um domínio de forma maleável, a fim de permitir reagrupamentos distintos, nos quais, a hierarquia dos fatores pode não ser a mesma. (Ex.; Domínio alpino, Domínio das sequências paleomesozóicas). As grandes bacias hidrográficas do Brasil, por exemplo, podem ser evidenciadas como domínios (BITTENCOURT ROSA et al. 2002).

Entre a terceira e a quarta grandeza situa-se a Região Natural. Os Picos da Europa constituem, no interior do Domínio cantábrico, uma região natural bem circunscrita que corresponde à individualização tectônica de um maciço calcário vigorosamente, compartimentado e carstificado (BERTRAND, 1968). As pequenas bacias hidrográficas brasileiras podem ser caracterizadas como Regiões Naturais.

O Geossistema ou Sistema Natural nas unidades inferiores, segundo Bertrand (1968) acentua o complexo geográfico e a dinâmica do conjunto. Ele corresponde a dados ecológicos estáveis, resultantes da combinação de fatores geológicos, geomorfológicos, pedológicos e da cobertura vegetal (Ex.: compartimentações de pequenas bacias hidrográficas, natureza das rochas e dos mantos superficiais, dinâmica das vertentes, valor do declive, entre outros). O Geofácies se confirma no aspecto fisionômico, e o Geótopo situa essa unidade no derradeiro nível da escala espacial. Na constituição de um mesmo geossistema, o geofácies corresponde então a uma parte fisionomicamente, homogênea onde se desenvolve uma mesma fase de evolução geral do geossistema. Os elementos inferiores necessitam de uma análise fracionada de laboratório (BERTRAND, 1968).

Neste trabalho seguimos o modelo hierárquico estabelecido por Bertrand (1968), para as unidades físicas da paisagem, e desta forma foi possível caracterizar num mapa geoambiental da área estudada, a unidade geoambiental maior intitulada como Região Natural 


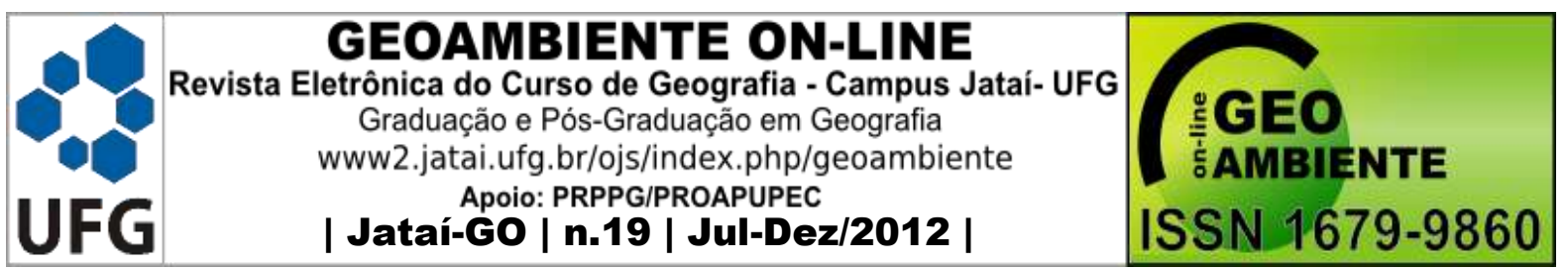

das Bacias Hidrográficas do Rio Boiadeiro e do Médio Rio Parnaíba compartimentada em três geossistemas, cuja qualificação está ligada a associação da geologia, do relevo, solos vegetação e as intervenções de natureza humana.

\section{3 - Região Natural das Bacias Hidrográficas do Rio Boiadeiro e do Médio Rio Parnaíba}

Os Três Geossistemas que fazem parte da Região Natural da Bacia Hidrográfica do Rio Boiadeiro e do Médio Rio Parnaíba estão discriminados na Figura 3.

Estes geossistemas apresentam feições onde predomina em relevo plano a montanhoso, às vezes, esculpido nas extremidades por escarpas íngremes, lisas, formadas por patamares estruturais escalonados, espelhos de falhas (slikensides), vales abertos, onde predomina uma sequência de rochas areníticas, basálticas e calcárias pertencentes às unidades litoestratigráficas oportunamente citadas, na parte referente à geologia local.

Figura 3 - Mapa Geoambiental da área de confluência dos rios Boiadeiro e Parnaíba e adjacências.

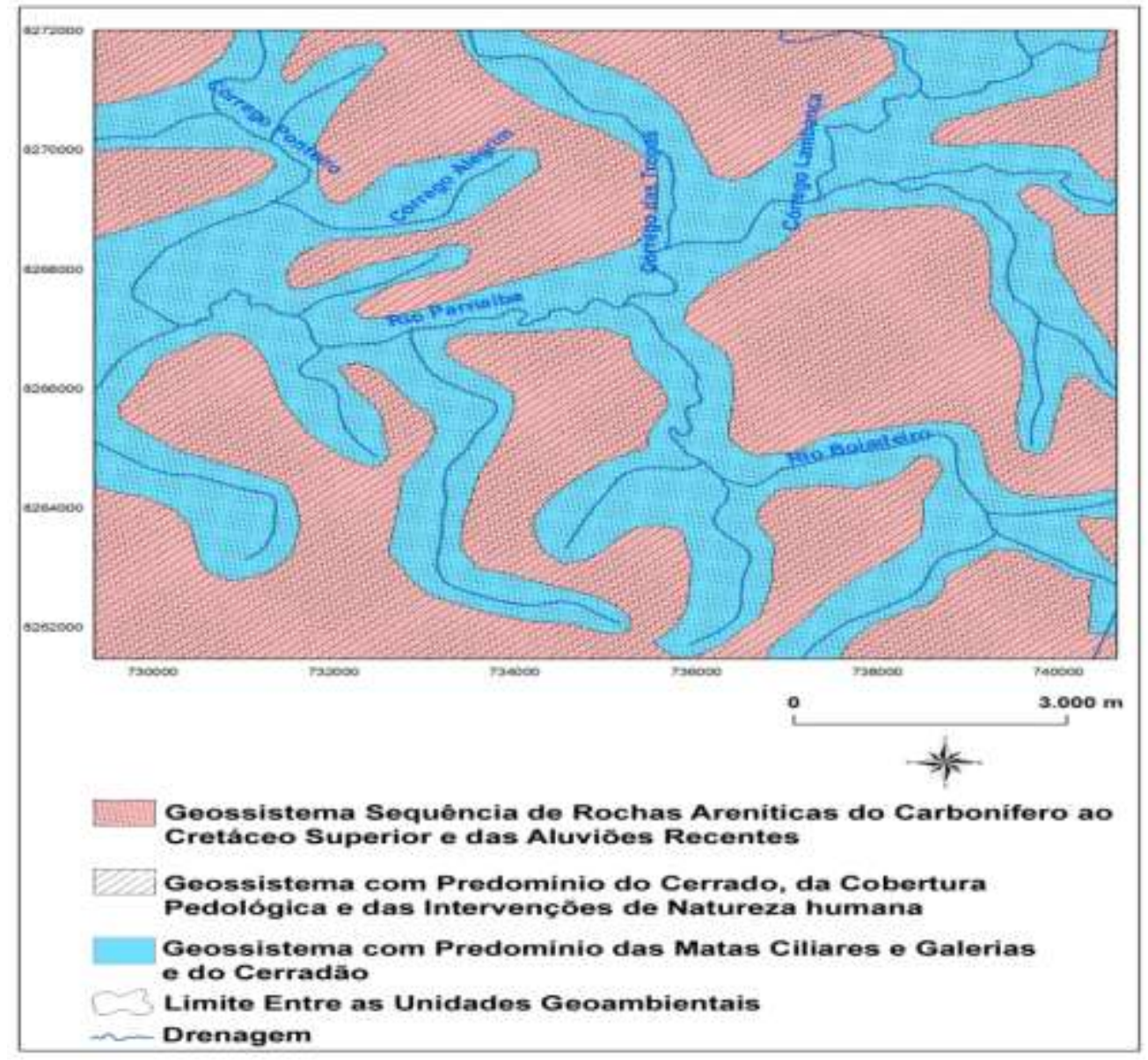

(Fonte: Bittencourt Rosa et al.2002 - Organizado por Valdenir Santana Araujo, 2012). 


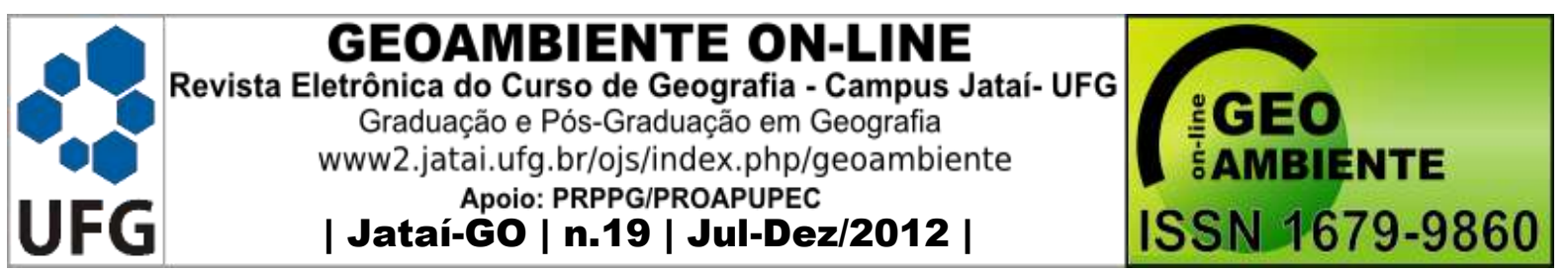

5.4 - Geossistema Sequência de Rochas Areníticas do Carbonífero ao Cretáceo Superior e das Aluviões Recentes

Esta unidade geoambiental está relatada à sequência litológica predominante em toda área estudada, onde predominam rochas areníticas avermelhadas, finas a muito finas, mais folhelhos, siltitos, argilitos e diamictitos pertencentes à Formação Aquidauana (Figura 4). Conglomerados basais avermelhados e róseos, intercalados com seixos de arenitos quartzíticos, camadas de argilas violetas e níveis de opalas esbranquiçadas, esverdeadas, cinzentas e azuladas. Leitos de opalas intercalados com siltitos esbranquiçados e avermelhados e de sílex esbranquiçados e azulados. Esses leitos são superpostos por camadas de arenitos avermelhados, esbranquiçados, beges a violetas, finos a muito finos, de siltitos finamente estratificados, arenosos, muito silicificados com diversas intercalações de sílex oolítico ou pisolítico, pertencentes à Formação Palermo. Basaltos da Formação Paredão Grande, Coberturas Detrito-Lateríticas e as Aluviões Recentes.

Figura 4 - Destaque no Geossistema Sequência de Rochas Areníticas do Carbonífero ao Cretáceo Superior e das Aluviões Recentes de maciço formado pela Formação Utiariti onde ocorrem conglomerados cíclicos, arenitos silicificados e silcretes na Região Natural da Bacia Hidrográfica do Rio Boiadeiro e do Médio Rio Parnaíba (Fotografia - Deocleciano Bittencourt rosa, março 2012).

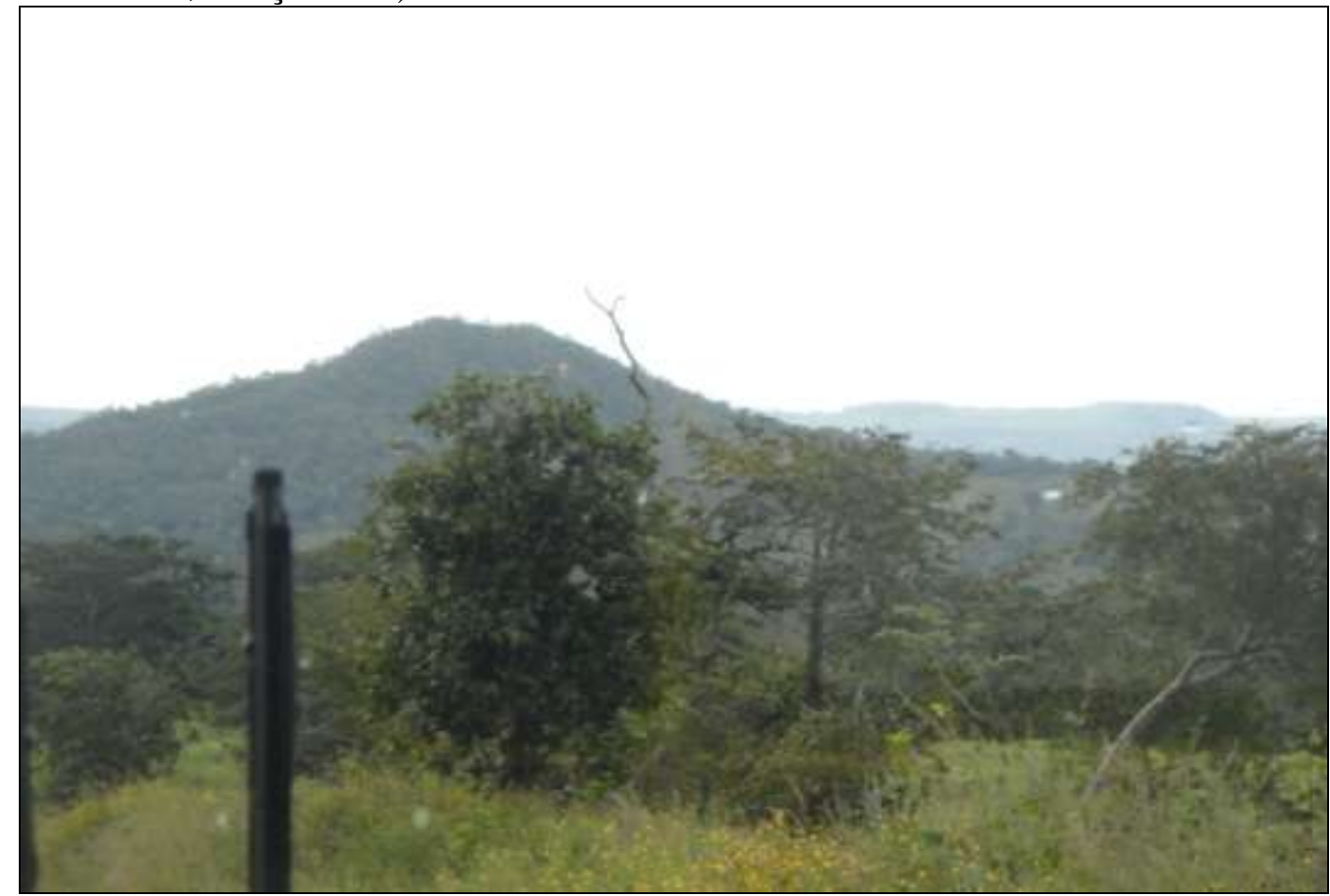




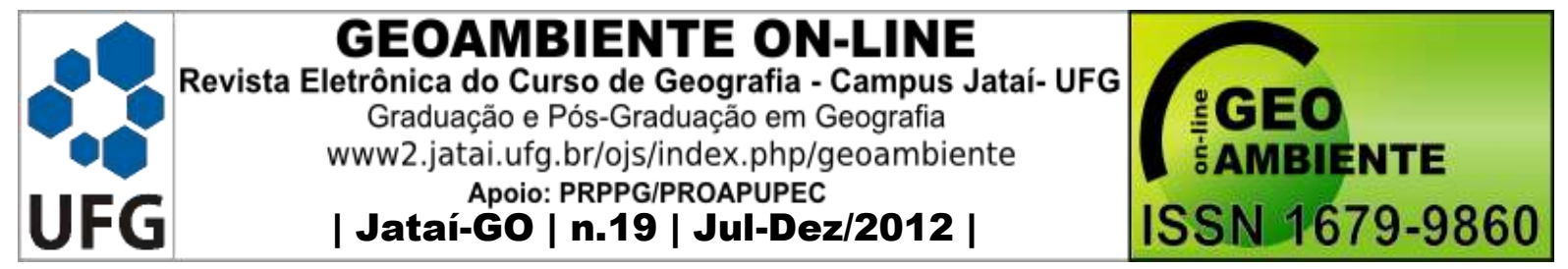

5.5 - Geossistema com Predomínio do Cerrado, da Cobertura Pedológica e das Intervenções de Natureza Humana

Neste geossistema estão posicionados: a cobertura vegetal do Cerrado, com presença de Campo Cerrado, Campo Sujo, Campo Limpo, e as Áreas Desmatadas para implantação de pastagens e cultivos, assim como para a retirada de material para a construção civil. Como solos que estão presentes neste geossistema destacam-se: Solos Concrecionários, Latossolos, Cambissolos, Neossolos Litólicos e Quartzarênicos, Nitossolos, Argissolos e Organossolos.

Concentrações de seixos quartzosos, concreções calcárias, seixos de basaltos, areia, silte, argila e minerais silicosos, estão presentes e na maior parte constituem as calhas do rio Boiadeiro e do rio Parnaíba, principalmente na área de confluência dos mesmos. Muitos destes cascalhos estão amontoados aleatoriamente nos locais das antigas cavas, da extração do calcário e nas áreas marginais do rio Boiadeiro, assim como nas circunvizinhanças.

\section{6 - Geossistema com Predomínio das Matas Ciliares e Galerias e do Cerradão}

É a unidade que corresponde à faixa de cobertura vegetal ainda existente nas encostas dos rios. Boiadeiro (Figura 5), Parnaíba e seus afluentes, principalmente em determinados trechos dos leitos que não foram degradados. 


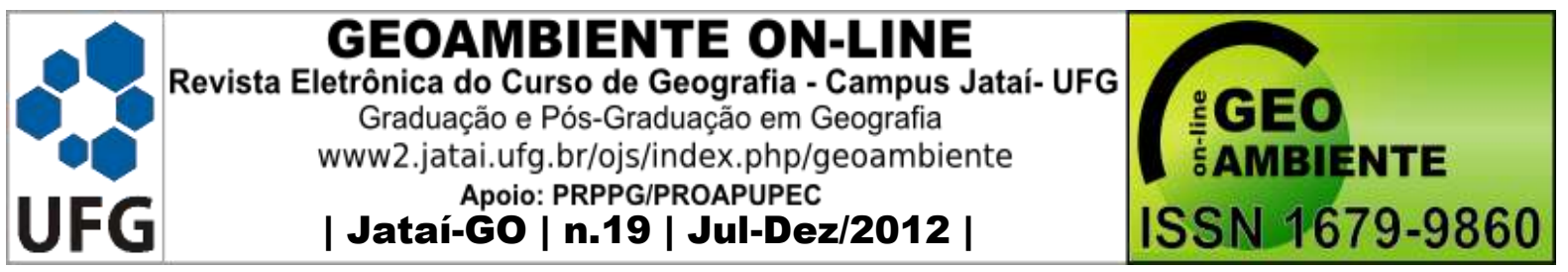

Figura 5 - Detalhe no Geossistema com Predomínio de Matas Ciliares e Matas Galerias e do Cerradão, que é a unidade que corresponde à faixa de cobertura vegetal ainda existente na encosta do vale do rio Boiadeiro, principalmente em determinados trechos do leito que não foram degradados. Local - Boiadeiro de Baixo (Fotografia - Jonathan Anderson de Paula Caldas, março 2012).

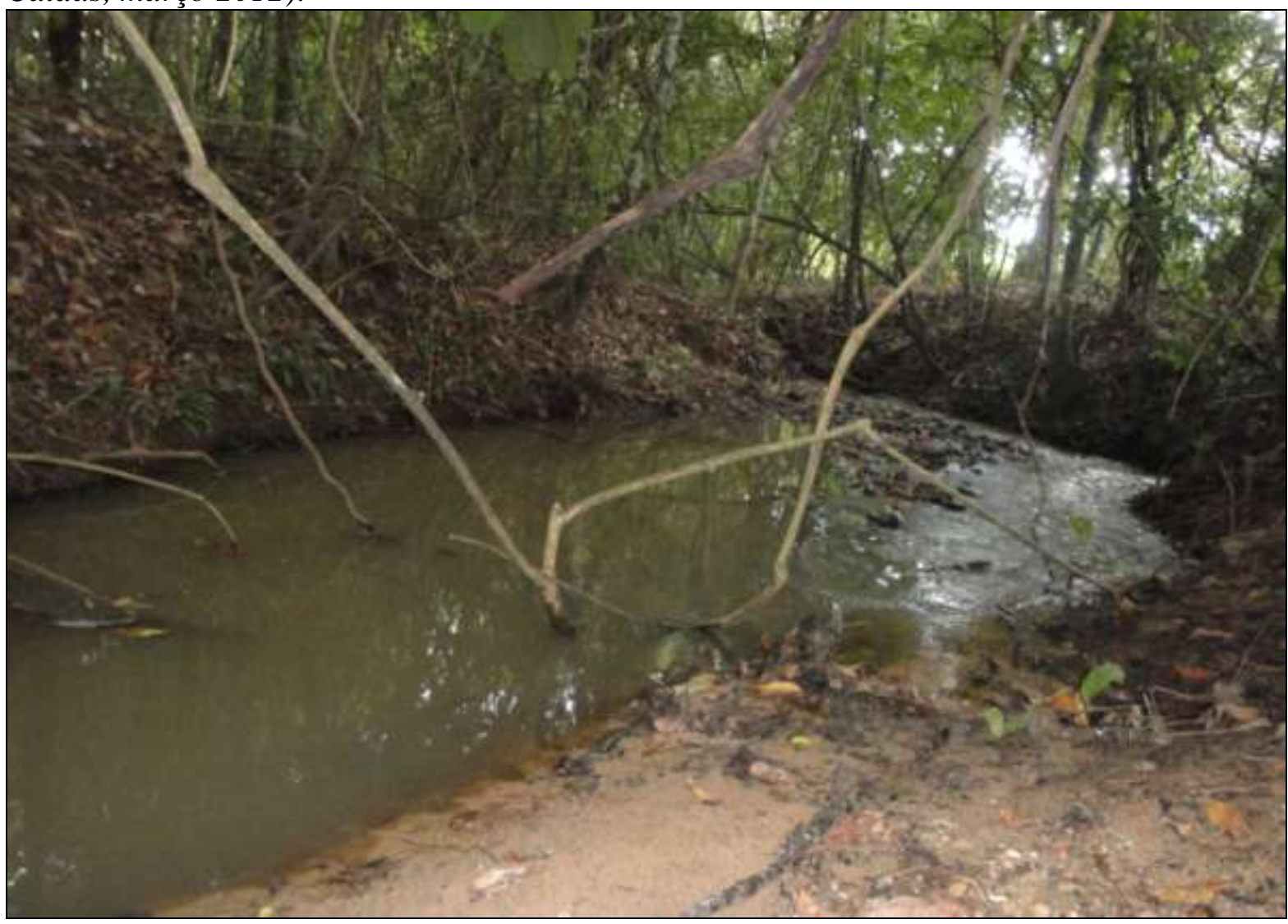

\section{6 - CONSIDERAÇÕES FINAIS}

A rede de drenagem estudada pertence à bacia hidrográfica do Alto Rio São Lourenço, cujas águas se dirigem para o Pantanal Mato-grossense, e desta forma suas características são marcantes em relação a esta presença, tanto no município em referência, como nas Planícies e Pantanais do São Lourenço - Cuiabá.

Os rios Boiadeiro e Parnaíba assim como seus tributários estabelecem uma relação direta com o município de Dom Aquino.

Mais uma vez fica patente à importância dos aspectos fisiográficos na caracterização de uma determinada área, isto porque uma descrição dos recursos naturais se constitui na atualidade num dos temas que mais se centraliza em resultados positivos, e depois a utilização 


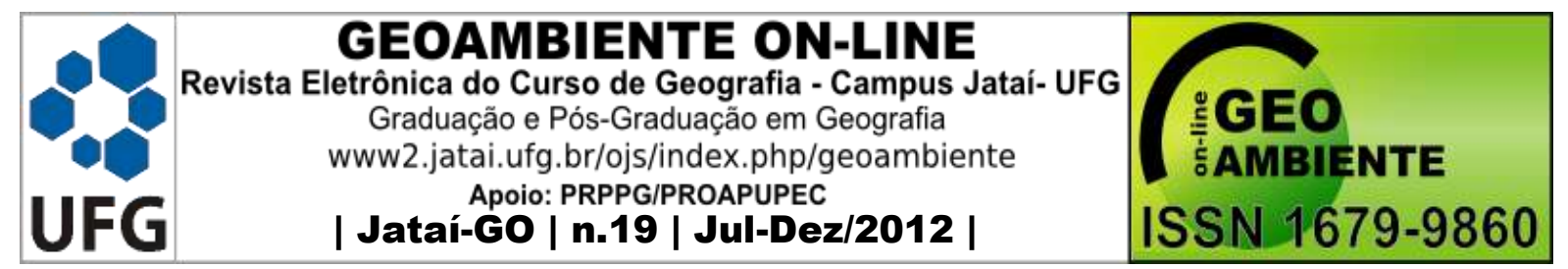

da divisão em unidades geoambientais que, notadamente, definem a constituição do meio ambiente, localmente. O solo principalmente é um recurso natural renovável, mas a sua reposição é lenta, por isso o uso racional levará a uma próspera e permanente qualidade de vida a sociedade. Neste sentido esta descrição fomenta bases para um melhor aproveitamento de seus recursos naturais, e recomendamos que ele sirva como base para outros trabalhos neste sentido nas regiões limítrofes.

Alguns proprietários de terras da região, em função das visitas técnicas dos órgãos fiscalizadores tais como o IBAMA - Instituto Brasileiro do Meio Ambiente e dos Recursos Naturais Renováveis, a SEMA - Secretaria Estadual do Meio Ambiente, MT e o DNPM Departamento Nacional da Produção Mineral aprenderam que a preservação do meio ambiente é um dos fatores de manutenção do seu próprio bem estar e da população residente, e podemos citar como exemplo as Matas Ciliares e Galerias do rio Boiadeiro, que são preservadas nos terrenos da Fazenda Água Escondida.

\section{7 - REFERÊNCIAS BIBLIOGRÁFICAS}

ALMEIDA, F. F. M. de. Reconhecimento geomórfico nos planaltos divisores das Bacias Amazônica e do Prata entre os meridianos $51^{\circ}$ e $56^{\circ} \mathrm{W}$ Gr., Revista Brasileira de Geografia, 10 (3): 397 - 440, Rio de Janeiro. 1948.

ALMEIDA, F. F. M. de. Geologia do centro leste mato-grossense. Bol. da Divisão de Geologia e Mineralogia, n. 15, p. 1 - 97, Rio de Janeiro, 1954.

ALMEIDA, F. F. M. de. Geologia do Centro-Oeste Matogrossense. Boletim da Divisão de Geologia e Mineralogia, Rio de Janeiro, (215): 1 - 133. 1964.

AMARAL, D. L.; FONZAR, B. C. e OLIVEIRA FILHO, L. C. As Regiões Fitoecológicas, sua Natureza e seus Recursos Econômicos. Folha SD.21/Cuiabá. BRASIL/Ministério das Minas e Energia. Secretaria Geral, Projeto RADAMBRASIL (Levantamento dos Recursos Naturais, 26), p. 401 - 452, Rio de Janeiro. 1982.

BARROS, A. M.; SILVA, R. W. de.; CARDOSO, O. R. F. A.; FREIRE, F. A.; SOUZA JUNIOR, J. J. de.; RIVETTI, M.; LUZ, D. S. da.; PALMEIRA, R. C. de. B. e TASSINARI, C. C. G. Geologia, Folha SD.21/Cuiabá. BRASIL/Ministério das Minas e Energia. Secretaria Geral, Projeto RADAMBRASIL (Levantamento dos Recursos Naturais, 26), p. 25 - 192, Rio de Janeiro. 1982. 


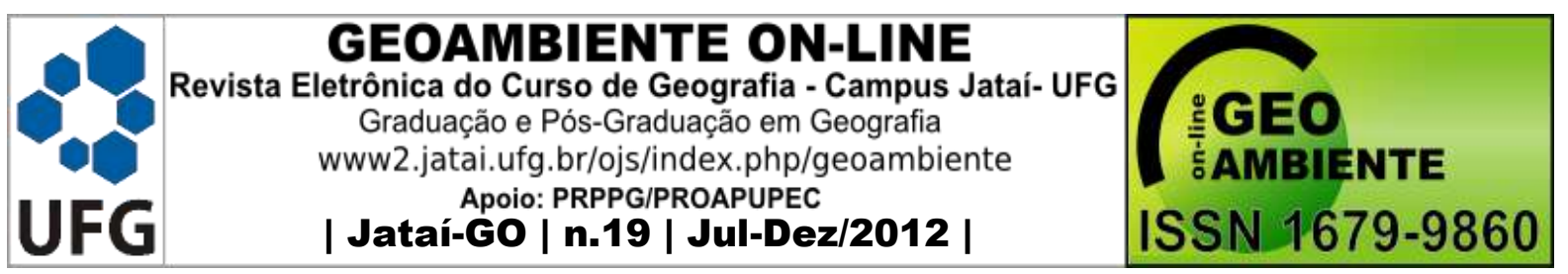

BERTALANFFY, L. V. Teoria Geral dos Sistemas (General System Theory). Editora Vozes Ltda, Petrópolis, RJ, 351 p. 1971.

BERTRAND, G. Paysage et Géographie Physique Globale. Esquisse Méthodologique. Revue Géographique des Pyrenées et du Sud Ouest, 39 (3) : 249 - 272, Toulouse, France. 1968.

BERTRAND, C. e BERTRAND, G. Le Géosysteme: Un Espace-Temps Anthropisé. Esquisse d'une temporalité environnementale. GEODE-UMR 5602, Centre National de la Recherche Scientifique et Université de Toulouse-Le Mirail, Toulouse, France, 6 p. 1991.

BITTENCOURT ROSA, D. Estudo das Rochas com Potencial para o Desenvolvimento de Crostas na Elaboração do Relevo nas Áreas das Bacias Hidrográficas dos Rios Alto Paraguai, Juruena e Teles Pires no Estado de Mato Grosso. Relatório Final de Pesquisa de Bolsa de Pós-Doutorado, Conselho Nacional de Desenvolvimento Científico e TecnológicoCNPq, Processo nº 200.181/2004-1, Brasília, DF, 184 p. 2005.

BITTENCOURT ROSA, D. Silcrètes et opales associées. Leur signification et leur contrôle dans l'élaboration des reliefs des districts de Dom Aquino et Poxoréu - Etat de Mato Grosso, Brésil. Thèse d'Habilitation à Diriger des Recherches - HDR, Université Rennes 2, Laboratoire COSTEL, 3 Volumes, Volume 2, 150 p, Rennes, France. 2009.

BITTENCOURT ROSA, D.; GELA, A.; ALVES, D. de. O.; MACEDO, M.; GARCIA NETTO, L. da. R.; NASCIMENTO, L. A.; PINTO, S. D. S.; BORGES, C. A.; ROSSETO, O. C.; TOCANTINS, N.; SANTOS, P. L. dos. e GERALDO, A. C. H. Um Estudo Geoambiental Comparativo das Características Morfoestruturais e Morfoesculturais nas Áreas das Bacias do Alto Rio Paraguai e do Rio Teles Pires no Estado de Mato Grosso. Projeto de Pesquisa, Relatório Final FAPEMAT/CNPq - Fundação de Amparo à Pesquisa do Estado de Mato Grosso/Conselho Nacional de Desenvolvimento Científico e Tecnológico, 319 p. 2002.

BRASIL/CPRM/SECMIN - Companhia de Pesquisa de Recursos Minerais - Serviço Geológico do Brasil/Secretaria de Mineração do Estado de Mato Grosso. Mapa Geológico do Estado de Mato Grosso.2004.

BRASIL/EMBRAPA. Empresa Brasileira de Pesquisa Agropecuária. Sistema Brasileiro de Classificação dos Solos. Brasília, DF, 429 p. 1999.

BRASIL. IBGE - Fundação Instituto Brasileiro de Geografia e Estatística. Zoneamento Ecológico-Econômico do Aglomerado Urbano de Goiânia. SEPLAN-Secretaria de Planejamento e Desenvolvimento Regional do Estado de Goiás. Diretoria de Geociências, Goiânia, GO. 1994. 


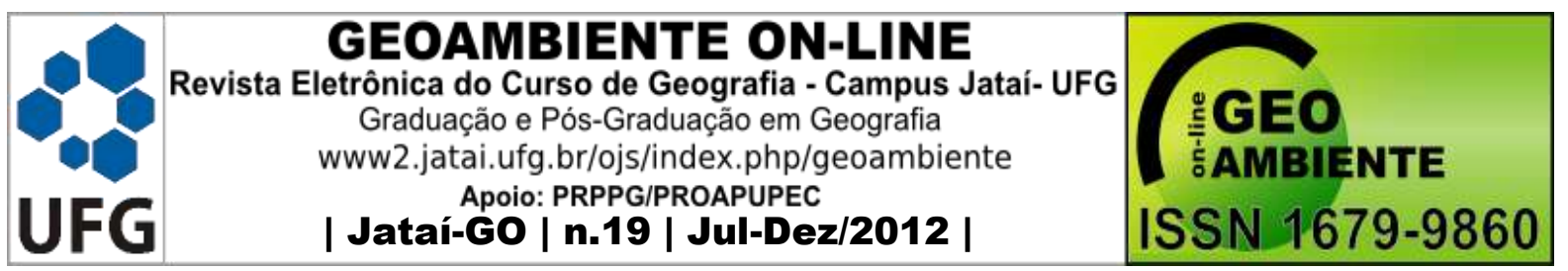

BRASIL/MAPA/EMBRAPA - Ministério da Agricultura, Pecuária e Abastecimento - Centro

Nacional de Pesquisa de Solos. Sistema Brasileiro de Classificação dos Solos. 2a Edição.

Revisada, Rio de Janeiro, RJ, 306 p. 2006

DEL'ARCO, D. M.; DEL'ARCO, J. de. O.; RIOS, A. J. W.; DAMBRÓS, L. A.; NOVAES, A. S. S. e PINTO, J. C. Mapa Geoambiental do Estado de Tocantins - Escala 1 :1000.000. In: SIMPÓSIO NACIONAL DE GEOGRAFIA FÍSICA APLICADA, 6, Goiânia, GO, Universidade Federal de Goiás, Anais do., p. 511 - 513, Goiânia, GO. 1995.

DURAND-DASTES, F. Climatologie. Encyclopaedia Universalis France, 4, p. 618 -624, Paris, France. 1968.

ESTIENNE, P. e GODARD, A. Climatologie. Armand Colin, Collection U, 365 p, Paris, France.1970.

FERREIRA, A. B. de. H. Novo Dicionário Aurélio da Língua Portuguesa. Nova Edição Revista e Aumentada, Editora Nova Fronteira, p. 1654, Rio de Janeiro, RJ. 2002.

FERREIRA, M. A. C. Aspectos Geoambientais Associados à Biodiversidade na Bacia do Médio Curso do Rio Parnaíba - Município de Dom Aquino - MT. Dissertação de Mestrado em Ecologia e Conservação da Biodiversidade. Instituto de Biociências, Universidade Federal de Mato Grosso - IB/UFMT, 123 p, Cuiabá, MT. 2002.

MAITELLI, G. T. Interações Atmosfera - Superfície. In: MORENO, G. e HIGA, T. C. S. (orgs). Geografia de Mato Grosso Território Sociedade Ambiente. Editora Entrelinhas, p. 238 -249, Cuiabá, MT. 2005.

MAXIMINIANO, A. C. A. Introdução à Administração. $6^{\mathrm{a}}$ Edição, revista e ampliada, Editora. Atlas, p. 63 - 64, São Paulo, SP. 2004.

MENDES, J. C. Elementos de Estratigrafia. Biblioteca de Ciências Naturais. Editora. T. A. Queiroz, São Paulo, SP, 567 p. 1984.

MOREIRA, M. L. C. e VASCONCELOS, T. N. N. Mato Grosso SOLOS E PAISAGENS. Editora Entrelinhas, 222 p, Cuiabá, MT.2007.

OliVEIRA, V. A. de.; AMARAL FILHO, Z. P. de. e VIEIRA, P. C. de. Pedologia (Levantamento Exploratório dos Solos), Folha SD-21/Cuiabá. BRASIL/Ministério de Minas e Energia. Secretaria Geral, Projeto RADAMBRASIL (Levantamento dos Recursos Naturais, 26), p. 257 - 400, Rio de Janeiro, RJ. 1982.

ROESSING, H. M.; NOVAES, J. A. C. de.; MOTTANA, C. E. e MONTORO, R. M. R. Uso Potencial da Terra, Folha SD.21/Cuiabá, BRASIL/Ministério de Minas e Energia. Secretaria 


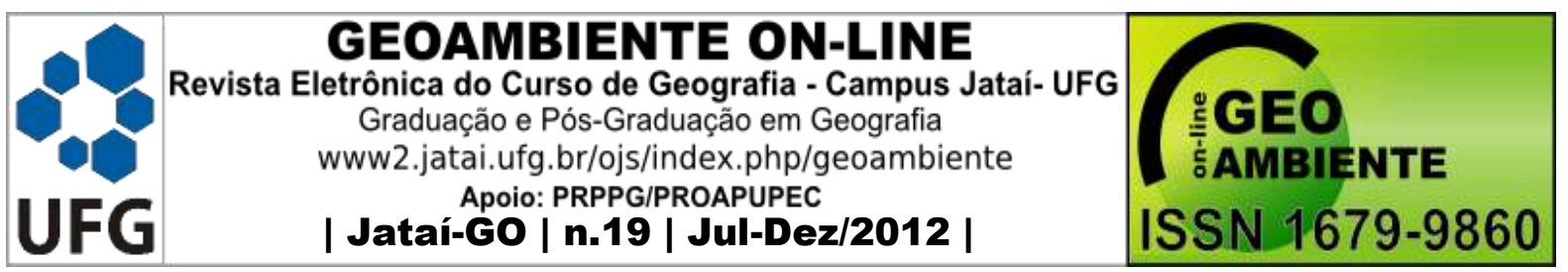

Geral, Projeto RADAMBRASIL, (Levantamento dos Recursos Naturais, 26), p. 453 - 540, Rio de Janeiro. 1982

ROSS, J. L. S. e SANTOS, L. M. dos. Geomorfologia. Folha SD.21/Cuiabá. BRASIL/Ministério das Minas e Energia. Secretaria Geral, Projeto RADAMBRASIL (Levantamento dos Recursos Naturais, 26), p. 156 - 193, Rio de Janeiro. 1982.

TARDY, Y. Le Cycle de L'Eau - Climats, Paléoclimats et Géochimie Globale. Masson Editeurs, 338 p, Paris. 1986.

VAILANT, C. Aspectos Geoambientais da Bacia Hidrográfica do Médio Rio Parnaíba nos Municípios de Campo Verde e Dom Aquino - Estado de Mato Grosso. Memória de Bacharelado em Geografia, Departamento de Geografia, Instituto de Ciências Humanas e Sociais/Universidade Federal de Mato Grosso - ICHS/UFMT, Cuiabá, MT, 88 p. 1999.

WESKA, R. K. Geologia da Região Diamantífera Poxoréu e Áreas Adjacentes, Mato Grosso. Tese de Doutoramento em Ciências, Instituto de Geociências, Universidade de São Paulo USP, São Paulo, SP, 219 p. 1996.

WESKA, R. K. Uma Síntese do Cretáceo Superior Mato-Grossense. In: Revista Geociências, V. 5, n. 1, p. 71 - 81. Universidade Estadual Paulista Júlio de Mesquita Filho - UNESP, São Paulo, SP. 2006.

WHITE, I. C. Relatório Final da Comissão de Estudos das Minas de Conservação de Carvão de Pedra do Brasil. Tradução de Carlos Moreira. Rio de Janeiro, Imprensa Nacional, 617 p. 1908. 